\title{
Synthesis and characterization of silica microsphere and their application in removal of uranium and thorium from water
}

\author{
H. Basu $\cdot$ R. K. Singhal $\cdot$ M. V. Pimple • \\ A. V. R. Reddy
}

Received: 5 August 2013/Revised: 31 January 2014/Accepted: 12 March 2014/Published online: 9 April 2014

(C) Islamic Azad University (IAU) 2014

\begin{abstract}
Uranium (U) and thorium (Th) are known to cause acute toxicological effects in human, and their compounds are potential occupational carcinogens. During this work, silica microspheres were used to decontaminate the traces of $\mathrm{U}$ and $\mathrm{Th}$ in different water sources originated from groundwater and lake water. Ultra-filtration technique was used to isolate the microsphere from the water samples. Silica microspheres were synthesized based on a polyvinylpyrrolidone involved emulsion polymerization and subsequent sol-gel process. The microspheres were characterized for their size by using dynamic light scattering, and presence of silicate structure is verified by recording their attenuated total reflectance-Fourier transform infrared spectrum. The surface morphologies of the prepared silica microspheres were studied by using scanning electron microscope. Water samples collected from the groundwater and lake water were spiked with $\mathrm{U}$ and $\mathrm{Th}$ in the concentration range of $100-1,000 \mathrm{ng} \mathrm{mL}^{-1}$. The results of batch sorption experiments suggest that silica microsphere is very effective at $\mathrm{pH} 3$, and sorption is more than $99.9 \%$. Equilibrium sorption follows Langmuir isotherms and the maximum $\mathrm{U}$, and Th uptake is 30 and $36 \mathrm{mg} \mathrm{g}^{-1}$, respectively. Major physicochemical characteristics of the water were monitored before and after the decontamination process. Experimental results show no significant variations in any of the measured parameters.
\end{abstract}

Keywords Silica microsphere $\cdot$ Groundwater $\cdot$ Lake water - Uranium $\cdot$ Thorium $\cdot$ Decontamination

H. Basu · R. K. Singhal ( $₫)$ · M. V. Pimple · A. V. R. Reddy

Analytical Chemistry Division, Mod Labs, Bhabha Atomic

Research Centre, Trombay, Bombay 400085, India

e-mail: rsinghal@barc.gov.in

\section{Introduction}

Uranium and thorium are important elements not only in industrial application but also in energy and environmental problems. In view of the extensive usage of uranium and thorium for various industrial purposes and their sub trace level releases through liquid effluents which in turn reflects into the various aquatic medium (Gok and Aytas 2009; Basu et al. 2011; Singhal et al. 2011a, b). As per the recent works carried out in India (Singh et al. 1995; Singh et al. 2008), many location in the northern part of India (Punjab and Haryana) elevated levels of $U$ was observed in groundwater. Although exact reasons of elevated level of $U$ in groundwater is not certain but various probable reasons are either because of localized mineralization process in which uranium from the host rock is preferentially leaching in the aquatic subsurface environment and reflected in the groundwater or some other anthropogenic activity in that region like use of localized phosphate fertilizer etc.

Removal of pollutants from aquatic medium using adsorption phenomenon is a common practice, in which the pollutants accumulate on any solid surface. In water treatment, the pollutants and any solid phase are, respectively, called adsorbates and adsorbent. For a few decades, various adsorbents have been developed and used for water treatment using different processes (Gupta and Ali 2006; Ali 2010, 2012, 2014; Ali et al. 2012). A large number of studies have been carried out by using silica microspheres for removal of various pollutants from aquatic environments including dyes (Hench and West 1990; Frank et al. 1998; Guangyu et al. 2007). They are very effective in removal as they have large surface area, narrow distribution of the pore size, well-defined and adjustable pore structure. These spheres can be obtained from the synthesis of the core-shell particles. Most methods of fabrication of 
hollow silica spheres involve removing the core by calcination or dissolution into solvents. This can be achieved as one-step process, which meant that the formation of the inorganic shells and the dissolution of core particles occurred in the same medium or in two different steps, i.e., formation of composite particle, followed by removal of inner structure leaving behind the core with hollow space (Wang et al. 2010; Zhuang et al. 2009; Jal et al. 2004).Previous investigations have demonstrated that polymeric microparticles and inorganic cores can be coated with layers of various materials, including silica, yttrium basic carbonate, and zirconium hydrous oxide, either by controlled surface precipitation reactions on the core particles or by direct surface reactions. These core-shell particles often exhibit properties that are substantially different from those of the templated core (for example, different surface chemical compositions, increased stability, higher surface area, and different magnetic and optical properties), thus making them attractive from both a scientific and a technological viewpoint. Applications for such particles are diverse, including capsule agents for drug delivery, catalysis, coatings, composite materials, and protecting sensitive agents such as enzymes and proteins (Zou et al. 2008; Rosaria et al. 2011; Zhang et al. 2008; Naseem and Tahir 2001; Srivastava et al. 1989; Bektas et al. 2004). Zinc from aqueous solutions was successfully obtained by using magnetite silica core-shell Nanoparticles (Emadi et al. 2013).

Precise determination of $U$ and $T h$ in environmental and biological samples is a challenging task. Both of the metal ions are known to cause acute toxicological effects in human, and their compounds are potential occupational carcinogens. In case of uranium, World Health Organization (WHO 2008) had put up a drinking water guidelines and fixed the maximum uranium concentration in drinking waters to be less than $15 \mu \mathrm{gL}^{-1}$ (WHO 2008; Copenhaver et al. 1992; Banks et al. 1995; Berner and Berner 1996; Porcelli and Swarzenski 2003). This limit of uranium is put up considering its heavy metal toxicity rather than radiological. Depending upon the localized geo-chemical environment, groundwater has $\mathrm{Th}$ in the range of 10-20 picomolar $(\mathrm{pM})$, whereas in seawater it is in $0.1-1 \mathrm{pM}$ concentration. In the case of thorium, the toxicity is given in the form of radiological one as $0.5 \mathrm{~Bq} \mathrm{~L}^{-1}$.

In this work, silica microspheres were synthesized by a polyvinylpyrrolidone (PVP) by using emulsion polymerization and subsequent sol-gel process. Decontamination of $\mathrm{U}$ and $\mathrm{Th}$ from groundwater and lake water in the concentration range of $100-1,000 \mu \mathrm{g} \mathrm{L}^{-1}$ were successfully carried out using silica microsphere. Effective separation of silica microspheres from the water samples was carried out by using ultra-filtration technique.
All the works discussed in this manuscript was carried out during December 2012 to October 2013 at Bhabha Atomic Research Centre, Trombay, Mumbai-400085, India.

\section{Materials and methods}

\section{Chemicals and reagents}

All chemicals used in this work were of analytical grade of Merck-Aldrich. Doubly distilled water (Millipore) was used throughout the experiment for the preparation of the reagents. Stock standard solutions $\left(1,000 \mathrm{mg} \mathrm{L}^{-1}\right)$ of uranium (VI) and thorium (IV) in $\mathrm{HNO}_{3}$ medium were used for the preparation of the experimental solutions. The $\mathrm{pH}$ adjustment was made with $5 \mathrm{M}$ nitric acid (for acidic $\mathrm{pH}$ values) or $5 \mathrm{M}$ sodium hydroxide (for basic $\mathrm{pH}$ values). The glassware used were kept in $5 \%$ nitric acid overnight and subsequently washed several times with double-distilled deionized water before using.

Preparation of polyvinylpyrrolidone (PVP) functionalized polystyrene (PS) latexes

The monodispersed PS particles were prepared by emulsion polymerization. Measured quantity of styrene $10 \mathrm{~g}$, PVP $(1.5 \mathrm{~g})$ and water $(90 \mathrm{~mL})$ were charged into a 250-mL Teflon autoclave. The solution was stirred and deoxygenated by bubbling $\mathrm{N}_{2}$ at room temperature for $30 \mathrm{~min}$. Then, the mixture was slowly heated to $70{ }^{\circ} \mathrm{C}$, followed by addition of $10 \mathrm{~g}$ of aqueous solution containing potassium peroxodisulfate $(0.1 \%)$, and the reaction was carried out at $70{ }^{\circ} \mathrm{C}$ for $24 \mathrm{~h}$ in an autoclave (Hench and West 1990; Frank et al. 1998; Guangyu et al. 2007).

Formation of silica-coated PS particles and silica microspheres

The polyvinylpyrrolidone (PVP) functionalized polystyrene latexes were reacted with tetraethyl orthosilicate (TEOS) in a solution of ammonia in ethanol to yield silicacoated latex particles in a seeded growth process. In a typical procedure, $\mathrm{NH}_{4} \mathrm{OH}$ solution and $\mathrm{PS}$ emulsion were added into ethanol under stirring, and the mixture was kept at $30{ }^{\circ} \mathrm{C}$. Then, $10 \mathrm{~mL}$ solution of the TEOS in ethanol was added slowly to the suspension under stirring at $30^{\circ} \mathrm{C}$ at a rate of $1 \mathrm{~mL} \mathrm{~h}^{-1}$ using a peristaltic pump. The reaction mixture was stirred at $30{ }^{\circ} \mathrm{C}$ for an additional $5 \mathrm{~h}$. After cooling to room temperature, the suspended particles were treated with toluene to dissolve the polystyrene and to make it porous and hollow (Frank et al. 1998). 
Measurement of mean hydrodynamic diameter of particle distribution of silica microspheres

Size distribution and zeta potential of the silica microsphere in water samples were studied by using Malvern Zetasizer Nano ZS. Measurements were taken by dynamic light scattering using $\mathrm{He}-\mathrm{Ne}$ laser with a power of $4.0 \mathrm{~mW}$ and wavelength $633 \mathrm{~nm}$. The intensity of the scattered light was measured using an avalanche photodiode detector at room temperature $\left(25^{\circ} \mathrm{C}\right)$ having a quantum efficiency $>50 \%$ at $633 \mathrm{~nm}$.

Preparation of contaminated potable water

Potable water samples having a $\mathrm{pH} 6.3$ were spiked with uranium $\left[\mathrm{UO}_{2}\left(\mathrm{NO}_{3}\right)_{2}\right]$ and thorium $\left[\mathrm{Th}\left(\mathrm{NO}_{3}\right)_{4}\right]$ in the range of $100-1,000 \mathrm{ng} \mathrm{mL}^{-1}$. $\mathrm{pH}$ of the samples was maintained at $3.0 \pm 0.2$. Silica microspheres $\left(10 \mathrm{mg} \mathrm{L}^{-1}\right)$ were added and stirred with the help of an electrical stirrer for $30 \mathrm{~min}$. The process water samples were then passed through ultrafiltration membrane having 500 Dalton cutoff inside a pressurized cell to separate the microspheres from the process water. $\mathrm{U}$ and $\mathrm{Th}$ from the microsphere were desorbed using $4 \mathrm{M} \mathrm{HNO}_{3}$.

\section{Measurement of $\mathrm{U}$ and $\mathrm{Th}$}

Determination of uranium and thorium was carried out by using simultaneous solid-state detector inductively coupled plasma optical emission spectrometer (ICP-OES, model ACTIVA, from Horiba Jobin-Yvon SAS, France). Intensity of emission was measured at two different wavelengths, i.e., 398.58 and $367.01 \mathrm{~nm}$ in the case of uranium, whereas thorium emission was measured at 401.913 and $283.232 \mathrm{~nm}$. The calibration of instrument was carried by using Aldrich standard solution of uranyl nitrate and thorium nitrate. ACTIVA utilizes a $2,048 \times 512$ pixel, ultra-low noise, high quantum efficiency charge-coupled device (CCD) solid-state detector. ACTIVA includes a unique optical design featuring a $0.64 \mathrm{~m}$ Czerny-Turner optical system and holographic gratings of 4,343 grooves per mm and 2,400 grooves per $\mathrm{mm}$. Covering the full $6 \mathrm{~mm}$ height of the plasma, "Normal Analytical Zone Multi-WAV" acquisition mode provides complete sample fingerprinting of 75 elements in less than $30 \mathrm{~s}$. It gives resolution up to $10 \mathrm{pm}$. Concentrations of uranium and thorium in different samples were also validated by using alpha spectrometry. Details of the same were discussed elsewhere (Singhal et al. 2011a, b).

Spectroscopic investigation

The Attenuated total reflectance-Fourier transform infrared (ATR-FTIR) spectrum of silica microsphere was recorded between 500 and $4,000 \mathrm{~cm}^{-1}$ by using Fourier transform spectrometer "Spectrum One (Bruker)" equipped with the universal ATR as an internal reflection accessory which have composite zinc selenide.

\section{Scanning electron microscope (SEM)}

The surface morphology of microsphere was studied using scanning electron microscopy coupled with energy dispersive X-ray fluorescence spectrometry (EDS) (Instrument Model No. VEGA MV 2300T). Before recording the surface morphology, gold coating was done on silica microsphere using mini sputter coater.

\section{Results and discussion}

The efficiency of separation of traces of uranium and thorium from the aquatic medium by using silica microsphere may severely be affected by the presence of others ions in medium and as well the size of the microsphere. Therefore, detailed characterization of the water sample was carried out.

\section{Characterization of aquatic medium}

Table 1 gives the concentration of various ions including $\mathrm{U}$ and Th along with other physicochemical characteristics of the water samples used in this work. At various stages of the experiments, concentration of these parameters was monitored to maintain the quality of the water to ensure its

Table 1 Variation in various physicochemical characteristics of the groundwater before and after the completion of the experiment

\begin{tabular}{|c|c|c|}
\hline \multirow[t]{2}{*}{ Parameters } & \multicolumn{2}{|l|}{ Variations } \\
\hline & $\begin{array}{l}\text { Feed } \\
\text { water }\end{array}$ & $\begin{array}{l}\text { Processed } \\
\text { water }\end{array}$ \\
\hline $\mathrm{pH}$ & $6.3-7.6$ & $6.5-7.3$ \\
\hline Conductance $(\mu \mathrm{S})$ & $230-290$ & $240-280$ \\
\hline Total hardness $\left(\mathrm{mg} \mathrm{L}^{-1}\right)$ & $70-90$ & $65-85$ \\
\hline $\mathrm{HCO}_{3}^{-}\left(\mathrm{mg} \mathrm{L}^{-1}\right)$ & $55-70$ & $55-70$ \\
\hline $\mathrm{Na}^{+}\left(\mathrm{mg} \mathrm{L}^{-1}\right)$ & $28-40$ & $35-45$ \\
\hline $\mathrm{Fe}^{3+}\left(\mathrm{mg} \mathrm{L}^{-1}\right)$ & $0.5-4$ & $0.4-3.4$ \\
\hline $\mathrm{Ca}^{2+}\left(\mathrm{mg} \mathrm{L}^{-1}\right)$ & $39.26-50$ & $44-54$ \\
\hline $\mathrm{K}^{+}\left(\mathrm{mg} \mathrm{L}^{-1}\right)$ & $0.7-1.2$ & $0.6-1.3$ \\
\hline $\begin{array}{l}\text { Dissolved organic carbon [DOC] } \\
\left(\mathrm{mg} \mathrm{L}^{-1}\right)\end{array}$ & $1.0-1.5$ & $1.0-1.6$ \\
\hline Total dissolved solid $\left(\mathrm{mg} \mathrm{L}^{-1}\right)$ & $112-120$ & $110-130$ \\
\hline Turbidity (NTU) & $3-5$ & $3-6$ \\
\hline DO [dissolved oxygen] $\left(\mathrm{mg} \mathrm{L}^{-1}\right)$ & $6.5-7.2$ & $6.4-7.2$ \\
\hline Uranium (ng mL $\mathrm{mL}^{-1}$ ) & $6-10$ & $11-12$ \\
\hline Thorium $\left(\mathrm{Bq} \mathrm{L}^{-1}\right)$ & BDL & BDL \\
\hline
\end{tabular}


suitability for the consumption by human being. From this table, it is clear that there is no domination of any particular geological system as there is no elevated level of any particular ion was observed.

\section{Formation of silica microspheres}

PVP is an amphiphilic, nonionic polymer soluble in water and many nonaqueous solvents which arises from the presence of a highly polar amide group within the pyrrolidone ring and a polar methylene and methine groups in the ring and along its backbone. PVP first participated in the polymerization reaction as a stabilizer or surfactant and then played a coupling agent role in the latter process. The PS particles were functionalized by PVP and incorporated

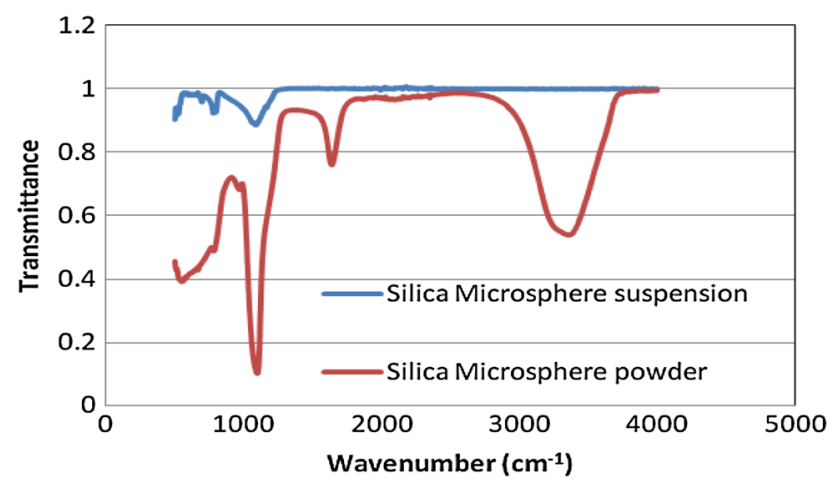

Fig. 1 Attenuated total reflectance-Fourier transform infra red (ATRFTIR) spectrum of silica microspheres hydrophilic PVP on their surfaces. The polystyrene particles were dissolved subsequently during the sol-gel coating process, followed by treatment with toluene to form silica microspheres. The details of the synthesis were discussed by Wang et al. 2010; Zhuang et al. 2009; Jal et al.2004. The size distribution of the silica microspheres as determined by Zetasizer nano (ZS) showed mean value of $220 \pm 20 \mathrm{~nm}$.

\section{Characterization of silica microsphere}

Figure 1 shows the attenuated total reflectance-Fourier transform infrared (ATR-FTIR) spectrum of the microspheres taken after separation by ultracentrifuge at 35,000 rpm [Model: Ultra 5.0, Make; Hanil, Korea]. Vibrational band at $1,100 \mathrm{~cm}^{-1}$ in Fig. 1 indicates the presence of $\mathrm{Si}-\mathrm{O}$ vibrational band. The surface morphology of the product was studied using scanning electron microscopy (SEM) coupled with energy dispersive X-ray fluorescence spectrometry (EDS) (Instrument Model No VEGA MV 2300T,). Two typical SEM images of the silica microsphere sample were shown in Fig. 2a, b. Image recorded after ultrasonication is shown in Fig. 2a from which it is clear that these microsphere are spherical nanoparticles, which are predominately agglomerated in aggregates with no specific shape as shown in Fig. $2 b$. Measurements in several SEM images obtained from distinct areas in the specimen showed that the average size of the $\mathrm{SiO}_{2}$ particles is about $200-240 \mathrm{~nm}$, with a very narrow size distribution. Chemical analysis conducted by the EDS
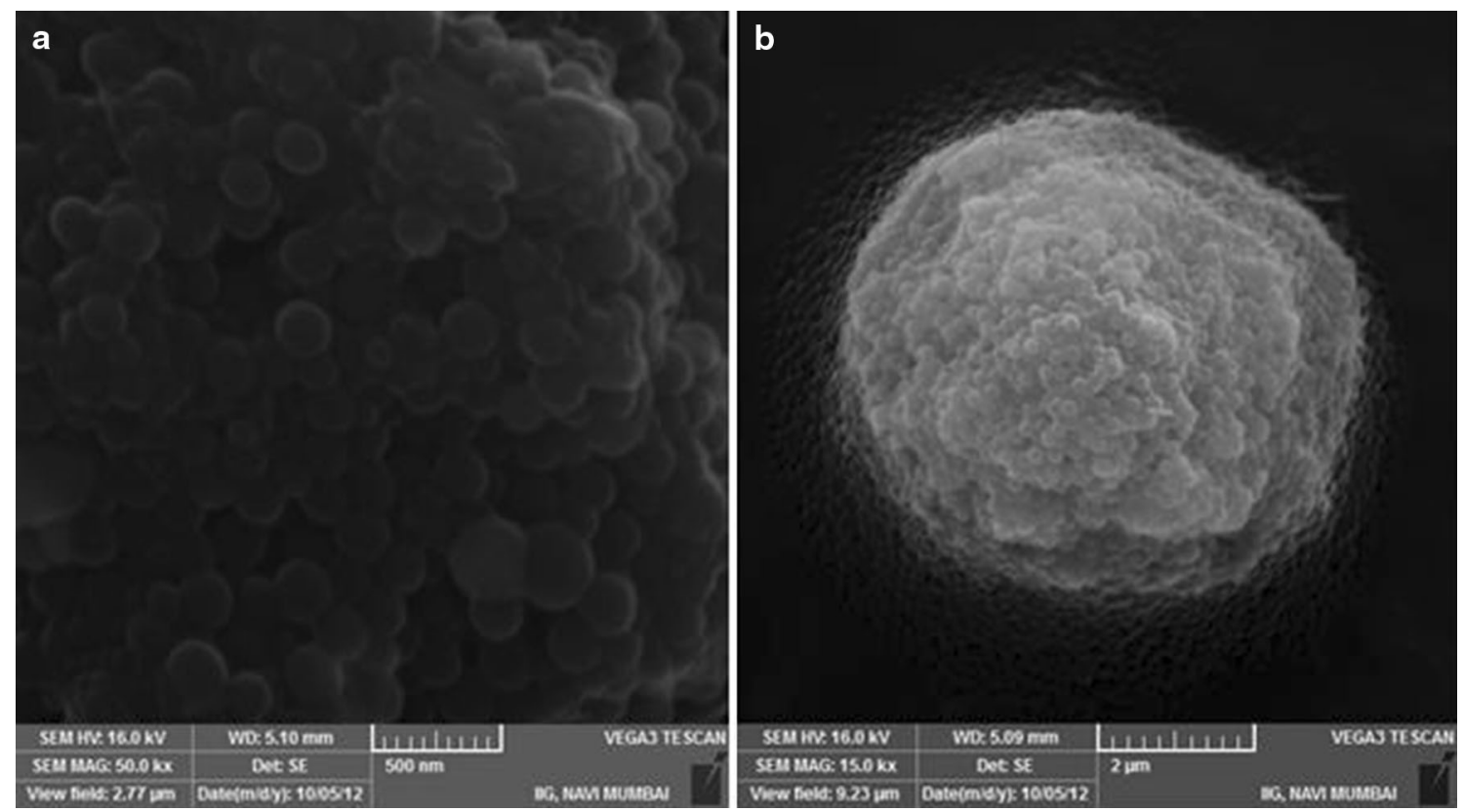

Fig. 2 SEM images of the silica microsphere $(\mathbf{a}, \mathbf{b})$ revealing the spherical morphology of the silica microsphere and their agglomeration 
Fig. 3 a Variation in percentage sorption of uranium (U) and thorium (Th) at $\mathrm{pH} 3$ at different concentrations of uranium and thorium.

b Variation in percentage desorption of uranium and thorium from silica microsphere with different amount of $3 \mathrm{M}$ $\mathrm{HNO}_{3}$
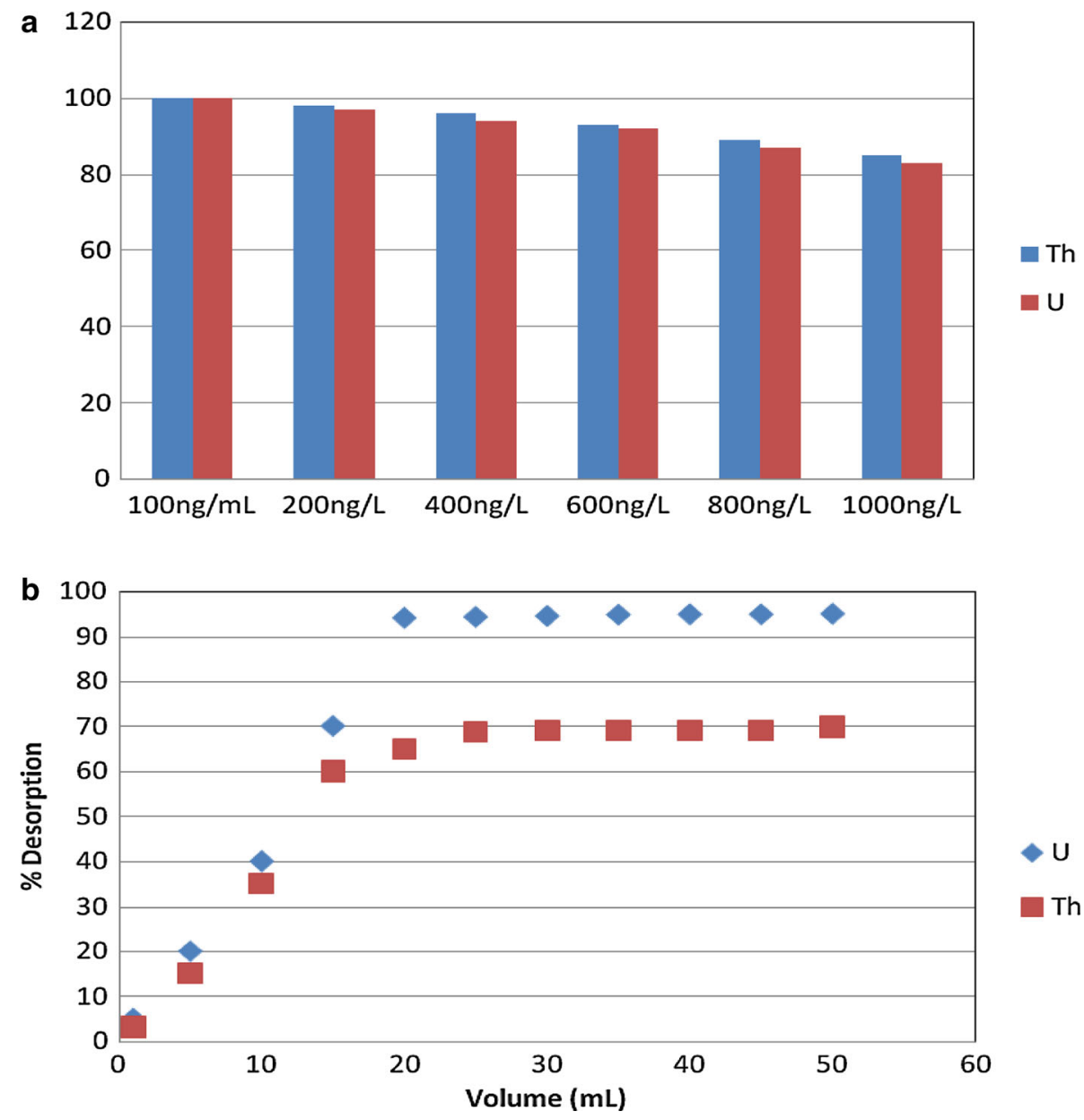

method confirmed that the particles are comprised of pure $\mathrm{SiO}_{2}$,with no indication of impurity elements (Frank et al. 1998; Guangyu et al. 2007).

$\mathrm{pH}$ optimization for sorption of $\mathrm{U}$ and $\mathrm{Th}$ by silica microsphere

In order to have effective sorption of $\mathrm{U}$ and $\mathrm{Th}$ by the silica microsphere, $\mathrm{pH}$ was optimized. The sorption profile of $\mathrm{U}$ and $\mathrm{Th}$ at concentration of $100 \mathrm{~Bq} \mathrm{~L}^{-1}$ was observed at different $\mathrm{pH}$. Experimental evidence clearly indicates that at $\mathrm{pH} 3$ more than $99 \%$ sorption of $\mathrm{U}$ and $\mathrm{Th}$ took place. In order to understand the various species of uranium present at $\mathrm{pH} \mathrm{3,5}$ and 6, work carried out by Wolery (1992) using computer program EQ3/6 was used. As per this uranium speciation model at $4 \times 10^{-4} \mathrm{M}$, initial uranium solutions showed that the uncomplexed uranyl ion $\mathrm{UO}_{2}{ }^{2+}$ dominates the $\mathrm{U}(\mathrm{VI})$ speciation at $\mathrm{pH} 3$ and with the increase in $\mathrm{pH}$, fraction of $\mathrm{UO}_{2}{ }^{2+}$ decreases sharply (Meinrath 1996, 1997; Elliot et al. 1986; Erdem et al. 2004; Reza et al. 2009). There is no change in sorption was observed with a change in $\mathrm{pH}$. This is because chemical properties of Th are relatively simple. Th has only one stable oxidation state, IV, under all redox conditions in natural waters, and Th(IV) ions are extremely particle reactive. The reactions and equilibrium equations for sorption of $\mathrm{Th}$ on silica are very similar to the proton exchange (Östhols 1995; Osthols et al. 1997; Quigley et al. 1996).

Probable mechanism for thorium sorption on silica surface

$2 \equiv \mathrm{SiOH}+\mathrm{Th}^{4+}+\mathrm{H}_{2} \mathrm{O}=(\equiv \mathrm{SiO})_{2} \mathrm{Th}^{2+}+2 \mathrm{H}^{+}$.

$2 \equiv \mathrm{SiOH}$ denotes a combination of two surface sites on the silica surface which are close enough to simultaneously chemically bind a sorbing $\mathrm{Th}^{4+}$ ion. However, at $\mathrm{pH} 8$ and above, the prevailing inorganic species of Th in groundwater are hydroxo and carbonato complexes, in approximately equal proportions. In fact, in organic-free solutions, thorium, an A-type metal ion, will strongly hydrolyze to form polyhydroxy colloidal complexes (Donat et al. 2005; Barbier et al. 2000). 
Fig. 4 a Model (Langumir) fitting of the experimental data for sorption of uranium at $\mathrm{pH} 3$. b Model (Langumir) fitting of the experimental data for sorption of thorium at $\mathrm{pH} 3$

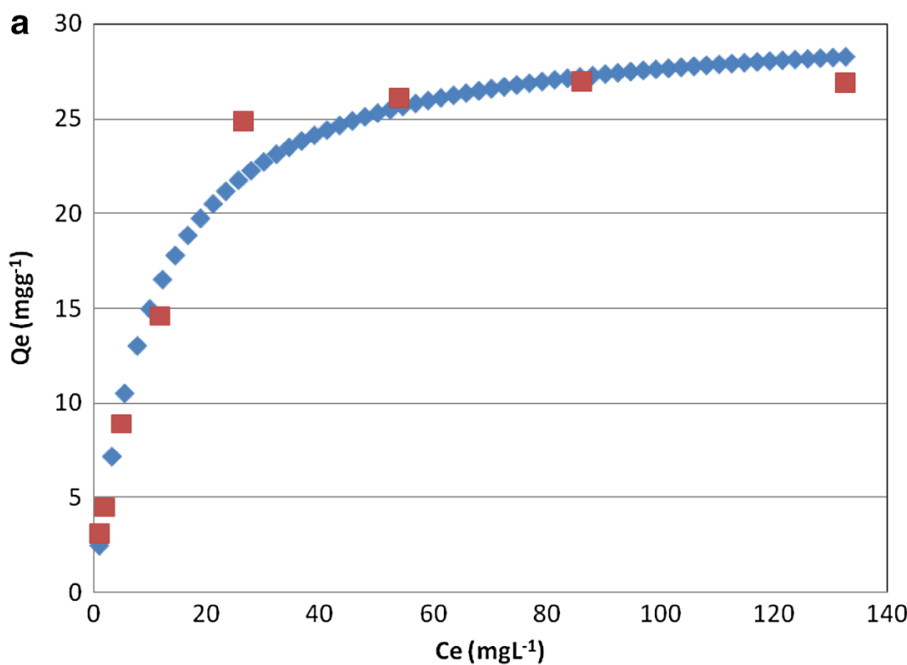

- Qe Langmuir fitting

Qe Experimental

Langmuir Equation: $\mathrm{Q}_{\mathrm{e}}=\mathrm{Q}_{\mathrm{o}} \mathrm{bC}_{\mathrm{e}} /\left(1+\mathrm{bC} \mathrm{C}_{\mathrm{e}}\right)$

$R^{2}=0.99$

Qe Langmuir fitting

Qe Experimental

Langmuir Equation: $\mathrm{Q}_{\mathrm{e}}=\mathrm{Q}_{\mathrm{o}} \mathrm{b} \mathrm{C}_{\mathrm{e}} /\left(1+\mathrm{bC} \mathrm{C}_{\mathrm{e}}\right)$

$R^{2}=0.99$
Variation of sorption of $U$ and Th on silica microsphere at different concentrations of $\mathrm{U}$ and $\mathrm{Th}$

Figure $3 \mathrm{a}$ gives the sorption profile of uranium and thorium at $\mathrm{pH} 3$ at six different concentrations $\left(100-1,000 \mathrm{ng} \mathrm{mL}{ }^{-1}\right)$ of $\mathrm{U}$ and $\mathrm{Th}$. All the experiment was carried out either with $U$ or Th. From this Figure, it is evident that more than $99 \%$ of $\mathrm{U}$ and Th got sorbed on the silica microspheres within $30 \mathrm{~min}$.

\section{Desorption of $\mathrm{U}$ and Th from silica microsphere}

The desorption of $\mathrm{U}$ and $\mathrm{Th}$ from the silica microsphere was done by $30 \mathrm{~mL}$ of $3 \mathrm{M} \mathrm{HNO}_{3}$. Figure $3 \mathrm{~b}$ shows the elution curve. From this elution curve, it is clear that only $95 \%$ sorbed $\mathrm{U}$ and $70 \%$ sorbed Th ions will be extracted back from the silica microsphere. Lower desorption of Th is due to highly particle reactive nature of $\mathrm{Th}^{4+}$, because of it Th is tightly bound within the silicate structure. After elution, the microsphere can be reused for the subsequent sorption of $\mathrm{U}$ and Th. Microsphere was found suitable for 30 cycles for $U$ and 20 cycles in case of Th. Thereafter, $25 \%$ degradation in the sorption capacity of silica microsphere was observed.

Evaluation of the sorption capacity of the silica microsphere

Sorption capacity of the microsphere was evaluated by carrying out the $\mathrm{U}$ and $\mathrm{Th}$ sorption experiments in the batch mode at $\mathrm{pH} \mathrm{3}$, and each time the level of uranium and thorium was increased with an increment of $5 \mathrm{mg} \mathrm{L}^{-1}$ of the sample was processed after initial equilibration time of $30 \mathrm{~min}$. After increasing the concentrations of $\mathrm{U}$ and $\mathrm{Th}$ above $30 \mathrm{mg}$ and $36 \mathrm{mg}$, respectively, elevated levels of $\mathrm{U}$ and Th were observed in the equilibrium solutions. Therefore, the sorption capacity evaluated as 0.12 and $0.16 \mathrm{mmol} \mathrm{g}^{-1}$ (on wet basis) in case of uranium and thorium respectively. Experimentally observed sorption capacity of uranium and thorium are very close to the 
Langumir constant $Q_{0}$ (see Fig. $4 \mathrm{a}, \mathrm{b}$ ), which is measure of the monolayer adsorption capacity, as obtained, $30 \pm 0.15$ and $36 \pm 0.15 \mathrm{mg} \mathrm{g}^{-1}$. As clear from the Fig. $4 \mathrm{a}, \mathrm{b}$ and $R^{2}$ values, experimental data are very close to the Langmuirtype adsorption model. As per the work carried out, Yousefia and coworker the maximum sorption capacity of the modified MCM-41 was found to be 47 and $49 \mathrm{mg} \mathrm{g}^{-1}$ for uranium (VI) and thorium (IV), respectively. Though these materials shows better sorption capability for uranium and thorium, but only disadvantage is elevated material cost, and the impact on drinking water quality was not tested in their work (Yousefia et al. 2009).

\section{Monitoring of the drinking water quality}

After having decontamination of $\mathrm{U}$ and $\mathrm{Th}$ from the water samples by using silica microsphere, various physicochemical characteristics of the process water were monitored. As its clear from Table 1 that there is only small variation in the parameters as compared to the feed solution. In view of this, it is inferred that effective decontamination was carried out without disturbing the water quality parameters.

\section{Conclusion}

Silica microspheres were synthesized using PVP and TEOS and applied as an effective sorbent for the removal of uranium and thorium from potable water in a batch process. The results of this study clearly showed the potential of this method to decontaminate various aquatic streams from $\mathrm{U}$ and $\mathrm{Th}$ without disturbing the water quality.

Acknowledgments The authors sincerely acknowledge the encouragement and guidance provided by Prof. B. N. Jagatap, Director chemistry group.

\section{References}

Ali I (2010) The quest for active carbon adsorbent substitutes: inexpensive adsorbents for toxic metal ions removal from wastewater. Sepn Purfn Rev 39:95-171

Ali I (2012) New generation adsorbents for water treatment. Chem Revs 112:5073-5091

Ali I (2014) Water treatment by adsorption columns: evaluation at ground level. Sepn Purfn Rev 43:175-2015

Ali I, Asim M, Tabrez A (2012) Low cost adsorbents for removal of organic pollutants from wastewater. J Environ Manag 113:170-183

Banks D, Røyset O, Strand T, Skarphagen H (1995) Radioelement (U, $\mathrm{Th}, \mathrm{Rn})$ concentrations in Norwegian bedrock groundwater. Environ Geol 25:165-180

Barbier F, Duc G, Petit RM (2000) Adsorption of lead and cadmium ions from aqueous solution to the montmorillonite/water interface. Colloids Surf A Physicochem Eng Aspects 166(1-3):153-159

Basu H, Singhal RK, Pimple MV, Manisha V, Bassan MKT, Reddy AVR, Mukherjee T (2011) Development of naturally occurring siliceous material for the preferential removal of thorium from U-Th from aquatic environment. J Radioanal Nucl Chem 289:231-237

Bektas N, Agim BA, Kara S (2004) Kinetic and equilibrium studies in removing lead ions from aqueous solutions by natural sepiolite. J Hazard Mater 112(1-2):115-122

Berner EK, Berner RA (1996) Global environment: water, air, and geo-chemical cycles. NJ Prentical Hall, Inc, Upper Saddle River 376

Copenhaver SA, Krishnaswami S, Turekian KK, Shaw H (1992) ${ }^{238}$ U and ${ }^{232} \mathrm{Th}$ series nuclides in groundwater from the $\mathrm{J}-13$ well at the Nevada Test Site: implication for ion retardation. Geophys Res Lett 19(13):1383-1386

Donat R, Akdogan A, Erdem E, Cetisli H (2005) Thermodynamics of lead and nickel adsorption onto natural bentonite from aqueous solution. J Colloid Interface Sci 268(1):43-52

Elliot HA, Liberati MR, Huang CP (1986) Competitive adsorption of heavy metals by soils. J Environ Qual 15:214-219

Emadi M, Shams E, Amini MK (2013) Removal of zinc from aqueous solutions by magnetite silica core-shell nanoparticles. J Chem 2013, Article ID 787682, 10 pages. http://dx.doi.org/10.1155/ 2013/787682

Erdem E, Karapinar N, Donat R (2004) The removal of heavy metal cations by natural zeolites. J Colloid Interface Sci 280:309-314

Frank C, Caruso RA, Mohwald H (1998) Nanoengineering of inorganic and hybrid hollow spheres by colloidal templating. Science 282:1111-1118

Gok C, Aytas S (2009) Biosorption of uranium(VI) from aqueous solution using calcium alginate beads. J Hazard Mater 168:369-375

Guangyu L, Zhang H, Yang X, Wang Y (2007) Facile synthesis of silica/polymer hybrid microspheres and hollow polymer microspheres. Polymer 48:5896-5904

Gupta VK, Ali I (2006) Advances in water treatment by adsorption technology. Nat Lond 1:2661-2667

Hench LL, West JK (1990) The sol-gel process. Chem Rev 90:33-72

Jal PK, Patel S, Mishra BK (2004) Chemical modification of silica surface by immobilization of functional groups for extractive concentration of metal ions. Talanta 62:1005-1028

Meinrath G (1996) Coordination of uranyl (VI) carbonate species in aqueous solutions. J Radioanal Nuc Chem 211:349-362

Meinrath G (1997) Uranium(VI) speciation by spectroscopy. J Radioanal Nuc Chem 224:119-126

Naseem R, Tahir SS (2001) Removal of Pb(II) from aqueous/acidic solutions by using bentonite as an adsorbent. Water Res 35(16):3982-3986

Östhols E (1995) Thorium sorption on amorphous silica. Geochim Cosmochim Acta 59:1235-1249

Osthols E, Manceau A, Farges F, Charlet L (1997) Adsorption of thorium on amorphous silica: an EXAFS study. J Colloid Interface Sci 194:10-21

Porcelli D, Swarzenski PW (2003) The behavior of U- and Th-series nuclides in groundwater. Rev Mineral Geochem 52:317-361

Quigley M, Honeyman BD, Santschi PH (1996) Thorium sorption in the marine environment: equilibrium partitioning at the hematite/ water interface, sorption/desorption kinetics and particle tracing. Aquat Geochem 1:277-301

Reza S, Seyed Y, Ahmadib J, Shemirania F, Jamalic MR, Niasari MS (2009) Simultaneous extraction and preconcentration of uranium and thorium in aqueous samples by new modified mesoporous silica prior to inductively coupled plasma optical emission spectrometry determination. Talanta 80:212-217 
Rosaria C, Sciortino M, Alonzo G, Schrijver AD, Pagliaro M (2011) From molecules to systems: sol-gel microencapsulation in silicabased materials. Chem Rev 111:765-789

Singh J, Singh L, Singh S (1995) High uranium contents observed in some drinking waters of Punjab, India. J Environ Radioact $76: 217-222$

Singh J, Harmanjit S, Singh S, Bajwa BS (2008) Estimation of uranium and radon concentration in some drinking water samples. Radiat Measurements 43(1):S523-S526

Singhal RK, Sharma PK, Bassan MKT, Basu H, Reddy AVR (2011a) Comparative Determination of Uranium in Rock Phosphates and Columbite by ICP-OES, alpha \& gamma spectrometry. J Radioanal Nucl Chem 288:149-156

Singhal RK, Basu H, Manish V, Reddy AVR, Mukherjee T (2011b) Removal of low level of Am-241 from potable water originated from different geochemical environments by calcium alginate. Desalination 280:313

Srivastava SK, Tyagi R, Pant N, Pal N (1989) Studies on the removal of some toxic metal ions. Part II. Removal of lead and cadmium by montmorillonite and kaolinite. Environ Technol Lett 10(3):275-282

Wang Y, Wang G, Wang H, Liang C, Cai W, Zhang L (2010) Chemical-template synthesis of micro/nanoscale magnesium silicate hollow spheres for waste-water treatment. Chem Eur J 16:3497-3503

Wolery T J, (1992) Report UCRLMA-110662 part 1: Lawrence Livermore National Laboratory, California, USA

World Health Organization (2008) Uranium in drinking water. WHO/ SDE/WSH/03.04/118

Yousefia SR, Ahmadib SJ, Farzaneh Reza S, Jamalic M, Niasari MS (2009) Simultaneous extraction and preconcentration of uranium and thorium in aqueous samples by new modified mesoporous silica prior to inductively coupled plasma optical emission spectrometry determination. Talanta 80:212-217

Zhang T, Ge J, Hu Y, Zhang Q, Aloni S, Yin Y (2008) Formation of hollow silica colloids through a spontaneous dissolutionregrowth process. Angew Chem 120:5890-5895

Zhuang Y, Yang Y, Xiang G, Wang X (2009) Magnesium silicate hollow nanostructures as highly efficient absorbents for toxic metal ions. J Phys Chem C 113:10441-10445

Zou H, Wu S, Ran Q, Shen J (2008) A simple and low-cost method for the preparation of monodisperse hollow silica spheres. J Phys Chem C (112):11623-11629 